\title{
La socioafectividad en el Derecho de las familias argentino. Su despliegue en la filiación por técnicas de reproducción humana asistida
}

\author{
Adriana Krasnow*
}

\begin{abstract}
RESUMEN
Este artículo describe la socioafectividad en el interior de los vínculos jurídicos que reconocen su origen en la filiación por técnicas de reproducción humana asistida, desde un abordaje que guarda sintonía con la visión constitucional y convencional en la que se inscribe el Código Civil y Comercial argentino. Con este objeto, se parte del análisis de la inserción de la socioafectividad en el derecho de las familias, mediante un estudio que considerando las distintas formas de vivir en familia, busca mostrar el despliegue de vínculos que reconocen su origen en el parentesco y en el afecto. En este marco, se analiza la receptividad de la socioafectividad en la filiación y, especialmente en una de sus fuentes, la filiación por técnicas de reproducción humana asistida. Con este propósito, se estudian aspectos que guardan una vinculación directa con la categoría conceptual en análisis, como los principios de la filiación; la triple filiación; la voluntad procreacional y la sociafectividad como elementos que definen el reconocimiento de la gestación solidaria en la justicia argentina. Todo lo expuesto se ilustra a lo largo del desarrollo con el relato de historias de vida que ponen de manifiesto el continuo contacto entre norma y realidad.
\end{abstract}

Persona - socioafectividad - filiación por técnicas de reproducción humana asistida

\section{The social affection in Right of Argentine families it deployment in to filiation by assisted buman reproduction techniques}

\begin{abstract}
This article describe the social affection in the inside of the legal ties which recognize its origin in the filiation by assisted human reproduction techniques, from an approach that is in tune with the constitutional and conventional view in which is based the Argentinian Civil and Commercial Code. With this objective, I part from the analysis of the insertion of the social affection in Family Law, through a study that considers different forms of living in a family,
\end{abstract}

* Abogada, Universidad Nacional de Rosario, Argentina. Doctora en Derecho, Universidad Nacional de Rosario, Argentina. Profesora de Derecho Civil, Universidad Nacional de Rosario e investigadora Conicet, Argentina. Correo electrónico: adrikrasnow@gmail.com.

Artículo recibido el 11 de enero de 2018 y aceptado para su publicación en este número el 18 de enero de 2019. 
looking to show the deployment of ties that recognize its origin in family relationship and affection. In this framework, is analyzed the reception of the social affection in the filiation and especially of one of it sources, the assisted human reproduction techniques. With this purpose, are studied aspects that have a direct tie with the conceptual category in analysis, as the principles of the filiation, the triple filiation, the procreational will and the social affection as the element that define the recognition of the solidarity gestation in the Argentinian justice. All the above is illustrated along the development of life stories that put in evidence the continuous contact between the rule and the reality.

Person - social affection - filiation by assisted reproduction techniques

\section{INTRODUCCIÓN}

El Código Civil y Comercial (en adelante, CCC) vigente en Argentina desde el 1 de agosto de 2015 responde a la protección de la persona en su unicidad, en sus relaciones de familia y en sus relaciones con lo social ${ }^{1}$. Es en este marco en el que logra plasmarse un ordenamiento que al reposar en principios y valores, permite elaborar respuestas para los distintos problemas que pueden suscitarse.

En sintonía con lo expresado, el método adoptado responde a su espíritu, al incluir un título preliminar en el que se refleja su impronta constitucional y convencional en los arts. $1^{\circ}$ a $3^{\circ}$, con el complemento de los principios reconocidos en los arts. $9^{\circ}$ a 14 . Seguidamente, la estructura se completa con seis Libros para cada sector, comprobándose cómo los principios y valores están presentes en cada uno de ellos ${ }^{2}$.

La descripción que precede se visualiza en toda la extensión que se asigna al Libro Segundo "Relaciones de familia". En su interior, se contemplan los institutos atendiendo a la protección de la persona sin importar el proyecto de vida que cada uno elija. Desde esta visión que atiende a la pluralidad y el respeto a la diversidad, se regulan los institutos considerando las distintas formas de vivir en familia que coexisten hoy; situación que motiva referir al "derecho de las familias" en reemplazo de su denominación tradicional "derecho de familia".

La apertura expuesta abre las puertas a la inserción de la socioafectividad y con ello resultan amparadas las relaciones familiares sustentadas en vínculos significativos que no siempre se completan con lazos de parentesco, sino que encuentran su fuente en el afecto.

Desde esta dimensión, nos proponemos describir la socioafectividad en el interior de los vínculos jurídicos que reconocen su origen en la filiación por técnicas de reproducción humana asistida (en adelante, TRHA), abordaje que estará precedido por una reseña que permita apreciar cómo se inserta la socioafectividad en el Derecho de las familias.

\footnotetext{
${ }^{1}$ Aprobado por Ley No 26.994, 2014.

${ }^{2}$ Veáse entre otros: Gil Domínguez, 2015a; Rosatti, 2016; Krasnow, 2017a y 2016 b.
} 


\section{LA SOCIOAFECTIVIDAD EN EL DERECHO DE LAS FAMILIAS}

\section{Dimensión actual}

Tradicionalmente, el Derecho de familia fue definido como el conjunto de normas jurídicas destinadas a regular los derechos subjetivos y deberes jurídicos que nacen de las relaciones jurídicas familiares ${ }^{3}$.

Los nuevos contornos que en el presente tiene este sector del Derecho privado, motiva preguntarse si este encuadre sigue vigente, tras la introducción de nuevas categorías conceptuales en la norma que se venían proyectando desde hace tiempo en la labor doctrinaria y jurisprudencial, destacándose entre ellas la "socioafectividad" .

Este término marco tiene un componente social y afectivo que no se asocia a parentesco. Su desarrollo responde a la receptividad de manifestaciones de vivir en familia que encuentran su cauce en vínculos de apego significativos para la persona que conviven o no con vínculos parentales. A modo de ejemplo mencionemos, entre otros, el vínculo entre convivientes; el vínculo entre el progenitor afín y el hijo afín sin existir entre ellos parentesco por afinidad por ausencia de matrimonio; vínculo entre padrino y ahijado no pariente; vínculo entre anciano y cuidador; vínculo entre el hijo adoptado bajo la forma simple o de integración con los parientes y referentes afectivos del o los adoptantes; vínculo entre la persona nacida por una TRHA con los dadores de material genético o mujer gestante.

Para mostrar el proceso de recepción de esta realidad en la norma, merece destacarse como antecedente, el art. 1584 del CC de Brasil: “(...) Si el juez verificara que el hijo no debe quedar bajo la guardia del padre o de la madre, deferirá la guardia a la persona que demuestre compatibilidad con la naturaleza de la medida, considerados, de preferencia, el grado de parentesco y las relaciones de afinidad y afectividad".

Si trasladamos la atención al Derecho argentino, se observa cómo con el tiempo se introduce su reconocimiento en normas de alcance general e individual, las que siguen como antecedente la Convención de los Derechos del Niño, en cuyo art. 5 establece:

Los Estados Partes respetarán las responsabilidades, los derechos y los deberes de los padres o, en su caso, de los miembros de la familia ampliada o de la comunidad, según establezca la costumbre local, de los tutores u otras personas encargadas legalmente del niño de impartirle, en consonancia con la evolución de sus facultades, dirección y orientación apropiadas para que el niño ejerza los derechos reconocidos en la presente Convención.

${ }^{3}$ Acerca del Derecho de las familias, véase entre otros: Kemelmajer et al. (2014); Krasnow (2017a); AzPiri (2016); Gil Domínguez et al. (2006).

${ }^{4}$ Respecto de socioafectividad, véase entre otros: Herrera (2014); Krasnow (2017a y 2017b); Lobos (2010); Mizrahi (2006). 
En sintonía con lo dispuesto en el instrumento internacional referenciado, la Ley nacional 26.061 de Protección Integral de los Derechos de Niñas, Niños y Adolescentes 5 y su decreto reglamentario $415 / 2006^{6}$, receptan la socioafectividad.

Las niñas, niños y adolescentes tienen derecho a un nombre, a una nacionalidad, a su lengua de origen, al conocimiento de quienes son sus padres, a la preservación de sus relaciones familiares de conformidad con la ley [...] (art. 11, Ley $\mathrm{N}^{0}$ 26.061). Se entenderá por 'familia o núcleo familiar', 'grupo familiar', 'grupo familiar de origen', 'medio familiar comunitario', y 'familia ampliada', además de los progenitores, a las personas vinculadas a los niños, niñas y adolescentes, a través de líneas de parentesco por consanguinidad o por afinidad, o con otros miembros de la familia ampliada. Podrá asimilarse al concepto de familia, a otros miembros de la comunidad que representen para la niña, niño o adolescente, vínculos significativos y afectivos en su historia personal como así también en su desarrollo, asistencia y protección [...] (art. 7, Dec. 415/2006).

En la misma sintonía es admisible citar la Ley nacional 26.657 sobre Salud Mental ${ }^{7}$, cuando en su art. 7 expresa:

El Estado reconoce a las personas con padecimiento mental los siguientes derechos: [...] b) Derecho a conocer y preservar su identidad, sus grupos de pertenencia, su genealogía y su historia; [...] e) Derecho a ser acompañado antes, durante y luego del tratamiento por sus familiares, otros afectos o a quien la persona con padecimiento mental designe; [...].

La reseña que se acompaña puede completarse con la labor que desde hace tiempo se viene registrando en la justicia argentina. Por su relevancia, se ilustra el desarrollo con el sumario de dos casos resueltos antes del CCC.

El más lejano en el tiempo, reconoció un régimen de comunicación entre la madre de crianza y el niño ${ }^{8}$ :

Corresponde distinguir el parentesco de sangre o legal, de aquel que se establece por la fuerza de los hechos, o los afectos y que cuenta con una aceptación social que lo legitima, aun cuando carezca de recepción legal [...] Toda vez que el vínculo materno filial socioafectivo que une a la accionante y el menor, ha nacido de una convención lícita entre la actora y los padres biológicos del niño -en el que se acordaron los roles que cada uno cumpliría dentro de la familia que construirían,

\footnotetext{
${ }^{5}$ Ley $\mathrm{N}^{\circ} 26.061,2005$.

${ }^{6}$ Decreto 415, 2006.

${ }^{7}$ Ley $\mathrm{N}^{\circ} 26.657,2010$.

${ }^{8}$ Juzgado Familia $4^{\circ}$ Nom. Córdoba, 28.6.2010.
} 
asignando un lugar duplicado de maternidad a la madre biológica y a la accionante-, permitiéndole así que participara y se involucrara, creando vínculos socioafectivos legítimos, no puede negarse el derecho del menor a tener y recibir el afecto de quien actuó como "madre de crianza" en sus primeros años de vida [...].

El otro caso es el primer antecedente de gestación solidaria en la justicia argentina? La jueza con estrategia jurídica acertada, introduce la socioafectividad ${ }^{10}$ :

[...] en la gestación por sustitución el elemento determinante es la voluntad procreacional [... $]$ La voluntad procreacional puede definirse como el querer engendrar un hijo, darle afecto y asumir la responsabilidad por su educación y crianza [...] La existencia de uniones afectivas donde la reproducción natural no resulta posible, obligan admitir la construcción de un parentesco que no se funde en bases biológicas, sino en la construcción de vínculos basados en la socioafectividad [...].

Todo lo expuesto muestra que el Derecho de las familias se amplía y puede definirse como el conjunto de normas jurídicas destinadas a regular los derechos subjetivos y deberes jurídicos que nacen de las relaciones jurídicas familiares que encuentran su origen en las relaciones de pareja, el parentesco y vínculos afectivos significativos.

Puede ilustrarse lo expuesto con la situación de un niño que al ser separado de su familia de origen por constatarse una grave vulneración de derechos, se dispone su inserción temporaria en una familia que asume su cuidado y protección. Si esta vinculación se extiende en el tiempo y con ello se consolidan vínculos afectivos entre el niño y quienes asumieron su cuidado, es posible preguntarse si después de definir su situación de adoptabilidad por no poder revertirse la realidad que exigió su separación de la familia de origen; corresponde poner fin al vínculo socioafectivo y definir su adopción o, por el contrario, corresponde conservarlo por medio del reconocimiento de la adopción a favor de los guardadores ${ }^{11}$.

Para elaborar una respuesta de la problemática expuesta que sea realizadora de los derechos del niño, se debe partir de una labor de interpretación de las normas de aplicación. En este marco nos encontramos ante normas rígidas que informan la prohibición de la entrega directa, precisando que la guarda de hecho no debe ser considerada a los fines de la adopción (art. 611, CCC argentino). Esta limitación se completa con la exigencia de la previa inscripción del o los pretenso/s adoptantes en el Registro y en la sanción de nulidad absoluta de la adopción cuando se otorgue a favor de quienes no

${ }^{9}$ Denominamos este procedimiento "gestación solidaria" en lugar de "gestación por sustitución", por entender que esta forma de nombrarla se corresponde con la finalidad que persigue su empleo. En la misma línea se enrolan Proyectos de ley con estado parlamentario (Proyecto 3202-D-2017 de 14 de junio, "Gestación solidaria"; Proyecto 5700-D-2016 de 31 de agosto, "Regulación de la Técnica de Gestación solidaria”).

${ }^{10}$ Juzgado Nacional $1^{\circ}$ instancia en lo Civil No 86, 18.6.2013.

11 Acerca de esta materia, ver: KRASNOw, 2018. 
se encuentren previamente inscriptos en el Registro Único de Aspirantes a Guarda con Fines de Adopción (arts. 600, inc. b y 634, inc. h, CCC argentino).

Surge el interrogante de si en estos casos debe siempre prevalecer la regla rígida de prohibición de la guarda de hecho por sobre el interés superior de la niña, niño o adolescente atravesado por esta disyuntiva o, por el contrario, es admisible apartarse de la prohibición y recurrir a un diálogo de fuentes orientado a la búsqueda de una respuesta acorde con la realidad que toca resolver.

Siendo coherentes con el desarrollo que precede, nuestra posición se ubica en la segunda alternativa propuesta, por entender que solo por este camino podrá accederse a una solución tuitiva de la persona. No debe olvidarse que el sistema de fuentes vigente en Argentina reposa en la protección de la persona que viene unida a la realización de sus derechos y, en función de ello, los arts. 1 a 3 del CCC argentino, ordenan que el intérprete debe emprender en cada caso una labor de interpretación e integración del sistema de fuentes en vinculación directa con los hechos del caso a resolver; arribando de este modo al dictado de una sentencia judicial razonable. Asimismo, corresponde señalar que cuando estemos ante un vínculo que comprende a un niño, la definición debe partir del respeto del principio de interés del niño (art. 3, CDN). En este sentido, se destacó en el interior de la doctrina chilena "la importancia de tratar de mantener el denominado statu quo de la persona menor de edad. Es decir, preservar al máximo la estabilidad personal y emocional que cualquier cambio, en este caso derivado de una ruptura familiar, pueda generar en los niños, niñas y adolescentes... el interés superior del niño, tal y como aparece configurado en el artículo 3, párrafo primero, del texto de la Convención, debe ser tomado en consideración en todas las decisiones y medidas que se adopten relacionadas, directa o indirectamente, con los niños, niñas o adolescentes, ya sean estos individual, grupal o colectivamente contemplados... El mentado principio tiene, por tanto, en el Derecho civil chileno, una composición necesariamente genérica, abierta y flexible, lo que permite su aplicación a las diversas situaciones jurídicas y sociales que se planteen como consecuencia de la variada realidad social que con anticipación no puede ser prevista en su totalidad y a los cambios que vayan suscitándose con el devenir del tiempo" 12 .

Si trasladamos esta reflexión al caso del cual partimos, podemos decir que la sentencia que crea el vínculo adoptivo será razonable si garantiza el derecho del niño a vivir y desarrollarse en una familia. Siendo así, resulta justo apartarse de la prohibición legal cuando la niña, el niño o adolescente encuentra la realización de este derecho en la familia de los guardadores. Cercenar esta posibilidad con fundamento en el apego a la norma, causaría un daño irreparable en la persona de la niña, niño o adolescente. Decimos que el daño sería irreparable, puesto que el tiempo de permanencia con los guardadores le permitió hacer realidad su derecho a

${ }^{12}$ Ravetllat Bellesté y Pinochet Olave, 2015, 927. 
vivir en familia y unido a esto fortalecer el proceso de desarrollo de la personalidad que se construye sobre la base de los elementos que nutren de manera continua la dimensión dinámica de la identidad.

\section{Despliegue de la socioafectividad}

Construir, interpretar y aplicar el Derecho de las familias preservando el valor humanidad, exige analizar de forma abierta aquellos datos de la realidad que impactan en la composición interna de cada familia.

En esta línea, la visión tolerante y plural en la que se enmarca la disciplina de referencia, indica que las familias se distinguen por las particularidades presentes en cada tipo, pero en todas ellas un elemento determinante de su nacimiento se encuentra en la existencia de un vínculo afectivo como punto de partida.

Así, cuando dos personas deciden emprender un proyecto de vida común mediante el matrimonio o la convivencia, es porque entre ellos existe un lazo de amor que motiva transitar una vida compartida. Este mismo sentimiento despertará posiblemente el deseo de proyectarse en hijos por el camino que posibilite concretarlo: la procreación natural, la procreación asistida o la adopción. El paso del tiempo y las circunstancias que lo atraviesen pueden debilitar este proyecto común o extinguirse por un hecho natural como la muerte de uno o de ambos. Quizá el devenir los encuentre ante el desafío de iniciar otra vida de pareja y así dar vida a una nueva familia matrimonial o convivencial.

Desde otro lugar podemos encontrarnos con personas solas que realizan el deseo de tener hijos por medio de la adopción o por un procedimiento de TRHA.

A lo enunciado es posible sumar el surgimiento de lazos afectivos que no reposan en vínculos de parentesco pero que resultan significativos para la persona y la familia, especialmente en el marco de la filiación por TRHA: a) dador/dadora de material genético cercano a la pareja de progenitores, quien sin tener voluntad procreacional construye con el niño o niña un vínculo de apego que por ser importante para ellos y la familia merece protección desde el derecho; b) mujer que desde una actitud altruista y solidaria, se compromete a gestar para que otro u otros concreten el deseo de ser progenitores, consolidándose en ciertas situaciones vínculos afectivos ajenos a la parentalidad, pero que igualmente resultan significativos para las personas que lo integran y que por tanto merecen amparo desde el derecho.

Como puede apreciarse la socioafectividad está presente en las familias y explica por qué todas ellas deben ser estudiadas desde esta realidad vivencial que nos atraviesa y comprende a todos.

En este marco, nos abocamos en los apartados que siguen al estudio de la socioafectividad en los vínculos creados con el empleo de TRHA. 


\section{LA SOCIOAFECTIVIDAD EN LA FILIACIÓN POR TRHA}

\section{Un encuadre previo necesario}

La procreación humana asistida puede ser definida como "[... ] los diferentes procedimientos que, en mayor o menor medida, pueden reemplazar o colaborar en uno o más pasos naturales del proceso de reproducción"13.

Mediante la misma, se penetra en el ámbito íntimo de la pareja o persona sola que decide tener un hijo por este camino. En algunos casos, la pareja recurre a las TRHA después de haber intentado, sin éxito, procrear naturalmente en el ámbito íntimo; mientras que en otras realidades -como personas solas o parejas de igual sexo- se emplea esta alternativa por razones ajenas a un problema de fertilidad.

En este contexto, corresponde distinguir las técnicas de baja complejidad y las técnicas de alta complejidad. En Argentina, el art. $2^{\circ}$ Decreto 956/2013 ${ }^{14}$ reglamentario de la Ley nacional 26.862 sobre Acceso integral a los procedimientos y técnicas médico-asistenciales de reproducción médicamente asistida ${ }^{15}$, define las dos clases:

Se consideran técnicas de baja complejidad a aquellas que tienen por objeto la unión entre óvulo y espermatozoide en el interior del sistema reproductor femenino, lograda a través de la inducción de ovulación, estimulación ovárica controlada, desencadenamiento de la ovulación e inseminación intrauterina, intracervical o intravaginal, con semen de la pareja o donante. Se entiende por técnicas de alta complejidad a aquellas donde la unión entre óvulo y espermatozoide tiene lugar por fuera del sistema reproductor femenino, incluyendo a la fecundación in vitro; la inyección intracitoplasmática de espermatozoide; la criopreservación de ovocitos y embriones; la donación de ovocitos y embriones y la vitrificación de tejidos reproductivos $[\ldots]$.

Si uno traslada la atención a las normas que regulan la filiación por TRHA en el CCC argentino, concluye que en sintonía con el principio de pluralidad, se define con un alcance amplio estos procedimientos en relación con sus destinarios. En esta línea, podrán hacer uso las parejas de igual o distinto sexo casadas o convivientes, como así también hombres y/o mujeres que no conforman pareja. Esto permite afirmar que resultan captadas las prácticas homólogas y las prácticas heterólogas.

Se estará ante una inseminación o fecundación homóloga cuando se recurre al empleo de material genético propio de la pareja. En este sector, quedan comprendidas dos variables: a) la inseminación o fecundación realizada en vida de la pareja, y b) la inseminación o fecundación post mortem. Si bien en estos casos coexisten armónicamente

\footnotetext{
${ }^{13}$ LuNA, 1999, p. 229.

${ }^{14}$ Decreto 953, 2013.

${ }^{15}$ Ley No 26.862, 2013.
} 
verdad genética y voluntad procreacional, el vínculo jurídico filial debe definirse en correspondencia con la voluntad procreacional.

Por otra parte, se estará frente a una inseminación o fecundación heteróloga cuando se utiliza material genético de un tercero dador, generalmente anónimo. A diferencia de la homóloga, hay disociación entre verdad genética y voluntad procreacional, definiéndose el vínculo jurídico filial también por el elemento volitivo.

La introducción que precede se hace con el objeto de mostrar que el hijo nacido e integrado a la familia alcanza un emplazamiento que, definido en función del elemento volitivo, crea vínculos jurídicos que no siempre reposan en la verdad genética, sino en el querer ser progenitor.

Además y como aspecto propio, es esencial destacar que en ciertas realidades se consolidan vínculos que no crean parentesco, pero sí lazos afectivos significativos para la persona. Replicando y ampliando los supuestos enunciados en el apartado anterior, puede mencionarse: a) la dación de material genético proveniente de gente allegada que ocupa un lugar importante en la vida de la persona nacida por este medio; b) dador anónimo que en algún momento de la vida inicia y consolida una relación con la persona nacida gracias a su aporte; c) mujer gestante en la gestación solidaria; d) hijo nacido como resultado de una fecundación post mortem que posteriormente entabla naturalmente lazos de apego con quien pasa a ser nueva pareja de la madre, siendo posible que estos lazos también se extiendan a sus familiares.

\section{Vinculación de la socioafectividad con los principios de la filiación}

Se parte de un encuadre de los principios para luego establecer lazos con la socioafectividad

\section{2.a) El principio de igualdad}

Las disposiciones generales del instituto en estudio se encuentran contenidas en el CCC argentino en el Capítulo 1 comprendido en el Título V "Filiación" 16 . Siguiendo el mismo orden que estableciera el CC derogado, se incorpora la filiación por TRHA como tercera fuente filial.

Así, en el art. 558 se establece que "La filiación puede tener lugar por naturaleza, mediante técnicas de reproducción humana asistida, o por adopción”.

Seguidamente y en resguardo del principio de igualdad, dispone que la filiación por naturaleza o por TRHA matrimonial y extramatrimonial, así como la adoptiva plena surten los mismos efectos.

${ }^{16}$ Para la filiación en el CCC véase, entre otros: FAmá (2012 y 2017); Herrera (2014); Krasnow (2012 y 2017a). 
Por otra parte y conservando el criterio consagrado en el art. 252 del CC derogado, se declara que ninguna persona puede tener más de dos vínculos filiales, cualquiera que sea la naturaleza de la filiación.

De lo dispuesto en la norma, se desprende que el principio de igualdad comprende el reconocimiento de los mismos efectos para todos los hijos cualquiera sea la fuente de la filiación y, al mismo tiempo, el derecho de toda persona de acceder a un emplazamiento en el doble vínculo filial.

En el marco de la filiación por naturaleza, la limitación al doble vínculo indica que, tratándose de una filiación matrimonial respecto de la cual un tercero pretenda ser parte del vínculo, solo podrá lograrlo si previo desplazamiento del progenitor legal por ausencia de vínculo genético, prueba el nexo genético que lo une con quien termina siendo su hijo. En cambio, en el supuesto de una filiación extramatrimonial -conforme a la cual el hijo fuera emplazado en el vínculo materno por vía legal, y el otro vínculo se definió por medio del reconocimiento-, si este último no se correspondiera con la verdad genética, quedaría abierta la posibilidad de plantear la acción de impugnación del reconocimiento, por parte de quienes tuvieran legitimación activa.

Trasladando la atención a la filiación por TRHA ${ }^{17}$, la referencia al doble vínculo se vincula con el elemento volitivo como determinante del emplazamiento, exteriorizado en el consentimiento informado y libre ${ }^{18}$. Siendo así, no se tiene en consideración al momento de establecer el vínculo filial en esta fuente, si se recurrió a material genético propio de la pareja o de tercero dador/dadora o se necesitó de una mujer que asumiera el lugar de gestante. Esta regla surge del art. 561 del CCC:

Los hijos nacidos de una mujer por las técnicas de reproducción humana asistida son también hijos del hombre o de la mujer que ha prestado su consentimiento informado y libre en los términos del artículo anterior, debidamente inscripto en el Registro del Estado Civil y Capacidad de las Personas, con independencia de quien haya aportado el material genético.

Lo dispuesto en el enunciado transcripto se vincula con lo establecido en el art. 577:

En los supuestos de técnicas de reproducción humana asistida, la determinación de la filiación se deriva del consentimiento previo, informado y libre, prestado de conformidad con lo dispuesto en este Código y en la ley especial. Cuando en el proceso reproductivo se utilicen gametos de terceros, no se genera vínculo jurídico alguno con estos, excepto a los fines de los impedimentos matrimoniales en los mismos términos de la adopción plena.

\footnotetext{
${ }^{17}$ Krasnow (2017b)

${ }^{18}$ De voluntad procreacional, véase entre otros: Gil Domínguez (2014); LAMm (2012); KraSNOw (2003).
} 
Del análisis conjunto, surge que la responsabilidad procreacional que en el marco jurídico se traduce en el conjunto de deberes y derechos que hacen al contenido de la responsabilidad parental, solo comprenderá a quienes tengan voluntad procreacional.

A modo de cierre de lo que será objeto de un desarrollo más extendido en otro apartado, corresponde señalar que los textos de los arts. 561 y 577 no hacen mención de la gestación solidaria. La razón de esto responde a que si bien en la etapa inicial de Anteproyecto de Reforma se reconocía este procedimiento en lo que en ese entonces era el art. 562, se borra del texto cuando el Proyecto recibe media sanción en la Cámara de Senadores ${ }^{19}$. Finalmente, el CCC se convierte en ley, manteniendo el texto aprobado en el Senado. Esto se hizo en un contexto donde además de su reconocimiento implícito en la Ley $\mathrm{N}^{\circ} 26.862$ y su decreto reglamentario 956/2013, se plantearon y resolvieron en la justicia argentina historias de vida atravesadas por esta práctica silenciada pero muy presente en la realidad ${ }^{20}$.

2.b) El respeto a la verdad genética como principio normativo en la filiación por naturaleza y el respeto por la voluntad procreacional como principio normativo en la filiación por TRHA

El CCC introduce el principio normativo que permite la determinación del vínculo filial en la filiación por TRHA. Con este aporte, la verdad genética constituye el elemento fundante del vínculo filial en la filiación por naturaleza; mientras que en la filiación por TRHA la voluntad procreacional definirá en todos los procedimientos el vínculo filial.

Otra nota que distingue a las dos fuentes se encuentra en la vinculación de cada una con tres aspectos que concurren conjunta o parcialmente en todo vínculo filial, como la voluntad de la unión sexual, la voluntad procreacional y la responsabilidad procreacional $^{21}$. En la filiación por naturaleza estos tres aspectos coexisten en los casos de parejas -casadas o convivientes-que deciden tener un hijo - unión sexual y voluntad procreacional-, asumiendo los deberes y derechos que le corresponde a cada uno, en su carácter de titulares de la responsabilidad parental. También puede presentarse el caso en el que la voluntad y responsabilidad procreacional se concentran en uno de los progenitores, como sería el supuesto del hijo extramatrimonial no reconocido. En este último caso, como la filiación y la responsabilidad parental son institutos diseñados en el interés del hijo, y este interés se efectiviza, en el marco de esta fuente, con un emplazamiento completo que guarde concordancia con la verdad genética, la norma civil prevé recursos que permiten sortear la ausencia de reconocimiento, como es el caso de la acción de reclamación de filiación extramatrimonial.

En cambio, en la filiación por TRHA, la concurrencia de los tres elementos se analiza sin considerar el elemento genético. Asimismo, se observan elementos que denotan

19 También se suprimió la fecundación post mortem.

${ }^{20}$ Referente a gestación solidaria, véase entre otros: LAMm (2015,2013, 2012, 2012); KemELmajer DE Carlucci et al. (2013, 2012); Gil Domínguez (2015); Famá (2017); Krasnow (2017, 2016a y 2016 b).

${ }^{21}$ Díaz de Guijarro, 1965, p. 21. 
una distancia con la filiación por naturaleza: 1) hay disociación entre unión sexual y procreación en la inseminación o fecundación asistida, situación que deriva en una disociación entre la voluntad de la unión sexual y voluntad procreacional; 2) el vínculo no se reduce a la pareja casada o conviviente, sino que comprende al equipo médico, que colabora desde el proceso reproductivo; 3) hay disociación entre verdad genética y voluntad procreacional cuando una pareja recurre a material genético de un tercero dador, ya que prima la voluntad sobre lo genético para la determinación del vínculo; 4) se concentra en una persona la voluntad y responsabilidad procreacional, sin unión sexual, cuando una mujer sola u hombre solo decide someterse a una TRHA; y 5) hay un proceso vital discontinuo en el supuesto de embriones crioconservados.

Trasladando la mirada a la socioafectividad, si bien resulta más visible en la filiación por TRHA, también concurre en la filiación por naturaleza. Pueden presentarse supuestos de desplazamiento por ausencia de nexo genético que se resuelven pacíficamente por contar con el respaldo de vínculos afectivos preexistentes. En este sentido, traemos un caso que es un espejo de lo expresado.

De los hechos surge que S. y A. contrajeron matrimonio el 8 de julio de 1994. El 6 de noviembre de 2001 nació M. quien fue inscripta como hija del matrimonio. Con el correr del tiempo y ante la duda sobre la paternidad de M., ambos cónyuges deciden realizar la prueba de ADN, prueba que se realiza el 7 de julio de 2007. Del resultado del estudio mencionado, se comprueba que el Sr. A. no es el padre biológico de M. Posteriormente, el matrimonio se divorcia, quedando desde entonces $M$. al cuidado de su madre. Cuando M. contaba con 6 años de edad, toma conocimiento de que su padre biológico es el Sr. Á. L. P., pareja a ese momento de su madre. En septiembre del 2015 M. concurrió a la Asesoría de Menores e Incapaces en compañía de su madre con el objeto de ser emplazada conforme su verdad de origen. El Sr. Á. L. P. se allana en todos los términos a la demanda de filiación contra él incoada, manifestando haberse sometido a una prueba de ADN y reconociendo ser el padre biológico de M. Por su parte, M. P. S. también se allana a la demanda entablada y reconoce que M. no es su hija biológica, conforme con el resultado de los estudios de ADN que fueran acompañados a la demanda. Relata que cuando tuvo la certeza de que la niña no era su hija le manifestó a la madre que estaba dispuesto a colaborar en todo aquello que le permitiera a M. el acceso a un emplazamiento conforme con su verdad. Asimismo, puso de resalto que con el ánimo de evitar causarle un daño, delegaba en la adolescente el camino judicial que correspondiera emprender. Conforme los hechos relatados y la prueba producida, la justicia hace lugar a la pretensión de la adolescente:

[...] La acción de reclamación de la filiación paterna debe admitirse, ya que quien goza de presunción de la paternidad matrimonial se allanó a la demanda y reconoció como válida la prueba de ADN que lo excluyó como padre biológico; a la vez que la adolescente accionante goza de posesión de estado respecto del demandado, la cual es reconocida por todas las partes y toma relevancia conforme lo dispone el art. 584 del CCC [...] La petición de una adolescente que promovió una acción de impugnación de la filiación matrimonial y reclamación de la paterna, tendiente 
a ser inscripta con su apellido materno debe admitirse, pues quedó acreditado su grado de madurez suficiente y su firme decisión en dicho sentido $[\ldots]^{22}$.

Como se puede observar, la respuesta judicial que la adolescente y su entorno familiar recibe en la justicia es el reflejo del respeto a la libertad y autonomía de la persona en el diseño de un plan de vida inclusivo de los vínculos afectivos constitutivos de su entramado familiar.

Trasladando la atención a la filiación por TRHA, la referencia al doble vínculo fortalece el elemento volitivo como determinante, sin considerar si se recurre al empleo de material genético propio de la pareja, de un tercero dador, o el proceso se completa con la participación de una mujer como gestante.

Entre las variables comprendidas, conforme con los términos y límites dispuestos en la norma, pueden mencionarse: a) gestación solidaria, donde, además de intervenir la pareja casada o conviviente - de distinto o igual sexo- o una persona -en cualquiera de los casos, con voluntad procreacional-, participa otra mujer que, sin voluntad procreacional, limita su intervención a prestar su vientre; sumándose en ciertas situaciones un tercero que aporta su material genético; b) pareja casada o conviviente -de distinto o igual sexo- con voluntad procreacional, que debe recurrir a material genético de un tercero dador o dadora - conocido o anónimo-, sin voluntad procreacional, y c) mujer sola, con voluntad procreacional, que logra un embarazo con el empleo de su material genético y semen de un tercero dador -conocido o no-, que no tiene voluntad procreacional, o con el uso de material genético tanto femenino como masculino, provenientes de dadores - conocidos o no-, que no cuentan con voluntad procreacional.

En los supuestos enunciados, se observan casos en los que la socioafectividad se rescata como argumento que permite arribar al dictado de sentencias razonables, como las dos historias de vida que se describen.

El primer caso se presenta en Viedma, ciudad ubicada en el sur argentino. Una pareja conviviente de hombres, pide en la justicia la autorización de implante de embriones de la pareja en el vientre de una mujer que se ofrece como gestante. La causa se radica en el Juzgado de Familia $\mathrm{N}^{0} 7$ de esta ciudad ${ }^{23}$.

Manifiestan encontrarse en unión convivencial hace catorce años y que siempre tuvieron la aspiración compartida de tener hijos. Relatan que en el 2015 conocieron a la mujer gestante y comenzó una amistad con ella y su familia. Al tiempo, nació la idea en la mujer de asumir el lugar de gestante y así colaborar en la realización del deseo de la pareja. Solicitan que se los autorice para iniciar el procedimiento que consistirá en la fecundación de un máximo de dos embriones con material genético de uno de ellos y óvulo de dadora, para luego ser implantados los embriones en la mujer portadora.

Suman a este pedido que con posterioridad al nacimiento, se ordene la inscripción del nacimiento, quedando emplazados ambos como progenitores. Manifiestan asumir

\footnotetext{
${ }^{22}$ Juzgado de $1^{\circ}$ Inst. Civil Comercial y Laboral Curuzú Cuatiá, 28.6.2016.

${ }^{23}$ Juzgado Familia $N^{\circ} 7$ Viedma, 6.7.2017.
} 
el compromiso de transmitir al hijo la verdad de su origen cuando cuente con la edad y madurez suficiente.

Después de producida la prueba que confirma la concurrencia de voluntad procreacional en la pareja, disposición de la gestante y su familia de prestarse al procedimiento teniendo conocimiento de sus efectos, salud psíquica y física en todos los intervinientes, acompañamiento del entorno social y familiar, condiciones habitacionales y económicas óptimas; se autoriza la realización de la práctica:

La autorización solicitada por un matrimonio conformado por dos hombres para la implantación de los embriones logrados mediante la técnica de ovodonación en el vientre de una mujer debe admitirse, en tanto ante la ausencia de útero, la única forma de garantizar efectivamente su voluntad procreacional deriva en la gestación por sustitución; máxime cuando de las pruebas producidas surge que la gestante tiene plena capacidad, fue debidamente informada, contó con asesoramiento legal, posee buena salud física y psíquica y cuenta con el apoyo de su círculo familiar [...]No teniendo tal voluntad la amiga de los comitentes, quien lleva a cabo el embarazo, la misma no desea ejercer el rol materno sino que su aporte ha tenido como finalidad altruista ayudar a que los comitentes concreten el ansiado deseo de ser padres. Destacando en todo momento que el rol de los progenitores se ejerce aun antes de que se geste y nazca el hijo, como así también que sus hijos conocen la verdad respecto de la gestación, manifestando los mismos que será 'su primo', 'el hijo de los tíos' [...].

Más cercano en el tiempo, se ubica el caso resuelto por una de las juezas que integran el Tribunal Colegiado de Familia No 4 de la ciudad de Rosario, Argentina, de 13 de octubre de $2017^{24}$. La Sra. M.V.M. en representación de sus hijos menores de edad, L.M. y V.M., inicia demanda de reclamación de filiación extramatrimonial post mortem, persiguiendo el emplazamiento de los niños como hijos de la Sra. S.G., quien falleciera el 1 de noviembre de 2012, contra sus herederos y/o sucesores.

M. V. M. y S. G. inician una relación de pareja en 1992. Al poco tiempo de iniciar la convivencia, nació en ambas el deseo de tener hijos. Con el recurso a material genético masculino de tercero dador anónimo, se concreta el embarazo de M. V. M. El 6 de diciembre de 2002 nacieron los hijos V. y L. M., los cuales fueron inscriptos como hijos de madre soltera por ausencia de norma que contemplara esta forma de vivir en pareja. Sin embargo, desde el nacimiento, la Sra. S. G. le dispensó a los niños trato filial como progenitora. Con la entrada en vigencia de la ley de matrimonio civil $\mathrm{N}^{\mathrm{o}} 26.618^{25}$ que extiende la posibilidad de casarse a las personas de igual sexo, la pareja planifica formalizar la unión. En setiembre de 2012, por directiva del Registro Civil, se admiten

\footnotetext{
${ }^{24}$ Tribunal Colegiado de Familia No 4 Rosario, 13.10.2017.

${ }^{25}$ Ley $\mathrm{N}^{\mathrm{o}} 26.618,2010$.
} 
los reconocimientos de los hijos provenientes de parejas de mujeres no casadas. Cuando estaban haciendo el trámite, S. G. fallece de muerte súbita el 1 de noviembre de 2012.

En este contexto, la Sra. M.V.M. en representación de sus hijos menores de edad, promueve la acción de reclamación de filiación extramatrimonial post mortem contra los herederos y/o sucesores de la Sra. S.G., con el objeto de que la causante sea emplazada como progenitora de los representados. Busca por este camino que se reconozca en el derecho el vínculo parental que reconoce en su origen la voluntad procreacional y el afecto. En la justicia se dijo:

[...] Que del análisis de la causa y de las pruebas producidas puede concluirse que ha sido acreditada la voluntad procreacional de la Sra. S. B. G., en relación a los niños V. M M. y L. D M., al tiempo de la realización de la técnica de fertilización y mantenida luego de nacimiento de estos, que se evidenció con la posesión de estado de hijos de ambos. En efecto [...] la voluntad procreacional no es más ni menos que el querer engendrar un hijo, darle afecto y asumir la responsabilidad de su educación y crianza; circunstancias todas acreditadas $[\ldots .$.$] .$

\section{Viabilidad de la triple filiación cuando la socioafectividad lo exige}

Retomando lo que se dijo al tratar en el apartado anterior el principio de igualdad, cuando se reclama una filiación que importa dejar sin efecto una anteriormente establecida, debe, previa o simultáneamente, ejercerse la correspondiente acción de filiación (art. 578, CCC).

Conforme esta regla, una persona no puede tener más de dos vínculos filiales. Sin embargo, en época cercana a la entrada en vigencia del CCC argentino, se ordenaron en sede administrativa dos inscripciones con triple filiación.

Una de las historias de vida comprende al matrimonio conformado por Susana y Valeria. La pareja y un amigo común participaron en el acto procreacional que permitió el nacimiento del niño Antonio. A diferencia de otros casos, donde la voluntad procreacional solo reposa en la pareja; en esta historia concurre la voluntad procreacional del matrimonio y del dador de material genético.

En este marco, los tres, contando con el patrocionio de la Federación Argentina de Lesbianas, Gays, Bisexuales y Trans (FALGBT), y la Mesa Nacional por la Igualdad y la Defensoría LGBT se presentaron ante el Registro Provincial de las Personas de la Provincia de Buenos Aires con el objetivo de alcanzar la inscripción de Antonio con tres vínculos filiales. El Registro hizo lugar al pedido, reconociéndole al niño dos madres y un padre. Asimismo, se dispuso que portara los tres apellidos. Entre los fundamentos que se esgrimieron por el órgano administrativo se rescata como relevante el derecho a la identidad de Antonio ${ }^{26}$.

\footnotetext{
${ }^{26}$ Citado en: Gil Domínguez, 2016, p. 1.
} 
Cercano en el tiempo, se presenta otro caso que se resulve con un criterio similar al anterior. Nos referimos, a la triple filiación que dispone el Registro de Estado Civil y Capacidad de las Personas de la Ciudad de Buenos Aires a favor de F.C.D.R.

Atendiendo a estas realidades, el Registro Nacional de las Personas decidió adaptar los formularios a la triple filiación, modificando los campos "Padre/Madre" por "Progenitor 1/Progenitor 2/Progenitor 3". Después de contextualizar el problema que se expone, se está en condiciones de expresar una posición respecto de este tema. Para ello se parte de recordar que como se expresó en el inicio, el CCC argentino al adherir a una perspectiva constitucional y convencional del Derecho privado, permite ser enmarcado como un Código de principios, puesto que en cada caso concreto el intérprete deberá elaborar una respuesta respetuosa de los principios y valores contenidos en las normas que se ubican en la cúspide de la pirámide jurídica (Constitución nacional e instrumentos internacionales de derechos humanos de igual jerarquía conforme lo dispuesto en el art. 75 , inc. 22 de la ley suprema).

Siendo así, puede sostenerse que cuando la historia de vida lo amerite deberá admitirse la triple filiación.

Decir esto, exige exponer las razones que llevaron al legislador a disponer como regla el doble vínculo filial y la conveniencia de que esta máxima se conserve como regla:

1. Oportunidad: la etapa de transición que se extendió entre el 2011 y 2015 -desde la presentación del Anteproyecto hasta la entrada en vigencia del CCC-, es una manifestación de las dificultades que se presentaron para llegar a un nuevo Código. Ciertas concesiones que se hicieron para concretar este anhelo se tradujeron en prohibiciones expresas, como así también en el enunciado de reglas y principios que abrieron el cauce a la labor de los intérpretes. Esto motiva que situaciones presentes en la realidad y no captadas en los enunciados del Código, encuentren respuestas en el marco del sistema, como la gestación solidaria, la fecundación post mortem, la delegación de la responsabilidad parental o guarda a un tercero no pariente y, también, la pluriparentalidad.

2. Ausencia de prohibición expresa: conforme el principio constitucional de legalidad todo lo que no está prohibido está permitido (art. 19, CN).

3. El reconocimiento de la socioafectividad.

4. El recurso a los arts. $1^{\circ}$ a $3^{\circ}$ del Título Preliminar. Conforme lo dispuesto en estos enunciados, los casos deben resolverse por medio de una labor de interpretación y aplicación que debe encauzarse desde una visión respetuosa del sistema de fuentes interno. A esto se suma el deber del juez de resolver con un criterio de razonabilidad. En los asuntos de pluriparentalidad, el juez arribará a una decisión razonable si después de vincular las normas de aplicación con las particularidades del caso concreto, arriba a una solución que hace efectivo tanto el mejor interés del niño o adolescente en cuestión como los derechos de las personas comprendidas.

Conforme lo expuesto, entendemos que no debería incorporarse al CCC argentino una norma expresa inclusiva de la pluriparentalidad, por entender que debilitaría la regla 
del doble vínculo filial dispuesta en el art. 558 del mencionado ordenamiento legal. Por tanto, se deberá recurrir a la justicia en supuestos como los descriptos, siendo el juez la autoridad competente para definir en cada caso la procedencia de la triple filiación.

\section{La voluntad procreacional y la socioafectividad como elementos que coadyuvan al reconocimiento de la gestación solidaria en la justicia argentina}

Como adelantamos en párrafos anteriores, cuando el Proyecto de Reforma de CCC de Argentina recibe media sanción en la Cámara de Senadores, se suprime del texto la gestación solidaria. Se conserva el mismo texto cuando el Código se convierte en ley ${ }^{27}$.

En este marco se destaca como señal de la exigencia de regulación la labor que se viene desplegando, exteriorizada en el desarrollo jurisprudencial.

En armonía con el sistema de fuentes interno, la justicia nacional con el respaldo de un sector importante en número de la doctrina interna ${ }^{28}$, asumió el compromiso de elaborar respuestas para quienes frente a una realidad concreta recurrieron a la gestación solidaria. Esto derivó en el dictado de pronunciamientos judiciales, muchos de estos constituyen modelos a seguir.

Como argumento común se destaca la valorización de la voluntad procreacional que junto con la socioafectividad permiten definir el emplazamiento filial en los supuestos de filiación por TRHA.

${ }^{27}$ En España, país que prohíbe expresamente este procedimiento, se observa cómo desde una posición rígida puesta en evidencia en el caso resuelto por la Sala de lo Civil del Tribunal Supremo de 6 de febrero de 2014 se observa cierta flexibilidad. Una muestra son los fallos dictados el 20 de octubre de 2016, haciendo lugar al pedido de los solicitantes después de arribar a una solución que fue el resultado de una interpretación integradora del sistema. Véase, LAmM (2017).

${ }^{28}$ En sentido contrario, se expresan voces calificadas: "Las sentencias tienen invariablemente una proyección política y social, de allí la necesaria moderación que se impone a la actividad jurisdiccional-. El límite entre control de constitucionalidad y convencionalidad y el Juez-legislador es bastante nítido. Una cosa es ordenar la inscripción del niño y otra muy distinta es desconocer un texto legislativo vigente que deliberadamente incluyó la regla de determinación por el parto para excluir el contrato de gestación por substitución del derecho argentino en texto que rige desde hace menos de un año. Es verdad que es un paso que ni siquiera el Tribunal Europeo de Derechos Humanos (Menesson, Labassé, citados por la Juez), uno de los Tribunales con una tendencia marcada a interpretar evolutivamente, admitió dar ... Es que la voluntad procreacional es el derecho de los fuertes, no de los débiles. Cuando la voluntad de los adultos determina la identidad de los niños, recortada de las legítimas cortapisas que le impone el derecho civil, el deseo adulto prima. Terminan afectándose los equilibrios democráticos que el derecho persigue en el interior de las relaciones de familia...”, BAsset (2016). En similar sentido, se sostuvo el “...repudio a la práctica de la maternidad subrogada, por la inmoralidad que de la misma resulta -sea que se la practique por dinero o en forma altruista - y por los daños que se le producen al niño. La misma no constituye la única vía para la realización efectiva de los derechos a la vida privada y familiar, a la integridad y libertad personal, a la igualdad y a conformar una familia, como se afirma infundadamente en el fallo, puesto que de no poder la mujer quedar embarazada, puede acceder a la adopción. Tampoco se puede en ese supuesto, afirmar que la no admisión de la maternidad subrogada constituya un acto discriminatorio con relación al derecho a la maternidad, pues la discriminación solo existe cuando se le niega a una persona lo que se le concede a otra en igualdad de circunstancias; lo que no ocurre en el caso en análisis...”, SAmbrizzi (2016). 
Asimismo, en las historias de vida en las que se recurrió a este procedimiento, se rescatan como elementos comunes: a) parejas en su mayoría unidas en matrimonio de distinto e igual sexo; b) en el mayor número, la mujer gestante tenía un vínculo de parentesco o afecto con la pareja; c) en la mayoría de los casos se recurrió a la justicia después del nacimiento y en un número menor se pidió en la justicia autorización tanto para iniciar el procedimiento como para que se ordene la inscripción producido el nacimiento; d) en todos los casos, la mujer gestante tuvo un propósito altruista y tenía hijos; e) en la mayoría de los casos, la justicia dispuso el deber de los progenitores de informar al hijo sobre su origen cuando cuente con la edad y grado de madurez suficiente; f) respetando el derecho a ser oído y a participar en el proceso, los hijos de la gestante con madurez suficiente expresaron su sentir en el proceso; g) en todos los casos, la mujer gestante no aportó su material genético.

Entre los elementos enunciados, se destacan como indicadores de la importancia de la socioafectividad los enunciados en los puntos b), d) y f).

De la descripción que precede, surge que el fin tuitivo siempre se focalizó en buscar soluciones que sean realizadoras del mejor interés de los niños-adolescentes alcanzados por el caso llevado a la justicia (persona por nacer e hijos de las personas con voluntad procreacional o de la mujer gestante). En esta línea y previo a la reseña de precedentes vinculados con el tema bajo estudio, se considera oportuno ilustar el desarrollo con un aporte proveniente de la doctrina chilena que si bien se sostiene sobre una base argumentativa contraria a la posición asumida en este trabajo respecto de la filiación por TRHA, coincide con el principio rector a tutelar, al decir: “... los conflictos que pudiesen suscitarse deben solucionarse dando preeminencia a los derechos del hijo. pues, en definitiva, los padres se someten a las TRA justamente para dar vida a un nuevo ser humano, pleno de dignidad y derechos pero que, por su propia condición, no puede hacerlos valer por sí mismo. La fragilidad de la vida en sus primeras etapas exige una especial protección y preocupación del derecho..."29.

Como lo anticipamos, trasladamos un breve relato de dos de los fallos más cercanos en el tiempo, los que se ajustan a los parámetros dispuestos por la Corte Interamericana de Derechos Humanos en el Caso Artavia Murillo ${ }^{30}$.

A los fines de no exceder el objeto de estudio, se limita el análisis a una descripción de cómo se fundamenta la viabilidad del procedimiento desde una estrategia que sustentada en la integración del sistema, encuentra respaldo en la concurrencia de la voluntad procreacional y la sociafectividad.

Se parte del caso que llega a conocimiento del Tribunal Colegiado de Familia $\mathrm{N}^{\circ} 7$ de la ciudad de Rosario, pronunciándose la jueza de trámite que le toca intervenir el 5 de diciembre de $2017^{31}$.

\footnotetext{
29 Turner Saelzer et al. (2000), p. 25.

${ }^{30}$ CIDH, Artavia Murillo y otros c/ Costa Rica, 28.11.2012.

31 Tribunal Colegiado de Familia No 7 Rosario, 5.12.2017.
} 
De los hechos surge que la Sra. M.E.H. y el Sr. I.O. solicitan autorización para la realización de transferencia de embriones mediante la gestación solidaria por parte de la Sra. A.H. y subsidiariamente, para el caso de prosperar la autorización, solicitan que se inscriba en el Registro de Estado Civil y Capacidad de las personas al niño/niña/s, concebido/s, a su nombre.

Relatan las dificultades que atravesaron para tener un hijo. El primer embarazo ocurrió en el 2010, pero se interrumpe al tercer mes de gestación, producto de la "trombofilia" que se diagnostica después de la pérdida. Transcurridos cinco meses de búsqueda del segundo embarazo, la pareja concibe gemelos y desde el inicio del embarazo la mujer hizo el tratamiento que previene los efectos de la enfermedad diagnosticada. En la semana dieciocho de gestación, se comprueba la falta de latido de uno de los embriones. En la semana veinticinco, la mujer es internada con un cuadro de HELLP, caracterizado por presión alta, fallas hepáticas, entre otros síntomas. El bebé era de muy bajo peso y la salud de ambos estaba en riesgo. El 4 de enero de 2011 se practicó una cesárea de urgencia, naciendo el hijo con muy bajo peso. El 11 de enero el bebé fallece.

Si bien el médico obstetra le recomendó a la pareja no buscar otro embarazo, decidieron hacer un último intento. En el segundo trimestre de gestación, se presentaron los mismos problemas que en los anteriores embarazos, comprobándose la pérdida de latidos del corazón de la hija en gestación.

Pasado más de un año del último embarazo, la hermana de la mujer le propone a la pareja prestarle su vientre. Su esposo y sus hijos la apoyaban y fueron estos últimos quienes permitieron vencer en los adultos los miedos y prejuicios que tenían respecto de la gestación solidaria.

Esta realidad familiar en la que por medio del afecto se intercambiaron roles con un fin legítimo y valioso como dar vida y con el solo impulso del amor que los unía, permitió iniciar otro camino válido para poner en ejercicio la voluntad procreacional. Pero para que esta voluntad esté fuerte para transitar el complejo camino que implicaba el procedimiento, pusieron en conocimiento de esto al resto de la familia y afectos. El apoyo incondicional que recibieron de todos, les permitió sumar la socioafectividad como elemento nutritivo para avanzar.

Es en este contexto cuando la jueza resuelve. Después de un análisis comprometido, responsable, coherente, consistente y respetuoso del sistema de fuentes interno vigente, se logra como resultado una norma individual ejemplar. Entre las notas que se vinculan con el tema, se rescatan:

[...] cabe aclarar que, ante la falta de regulación expresa respecto de la pretensión esgrimida, dada la delicada sensibilidad del tema y los fundamentales derechos en juego, nos obliga a realizar el análisis de la situación actual, a la luz del ordenamiento jurídico en general, desde una visión integradora y en diálogo de fuentes internas y convencionales [...] no existe norma legal expresa que prohíba la gestación por sustitución, ni que disponga sanción de nulidad como consecuencia de su utilización. Por consiguiente, debo entender que se trata de una TRHA permitida en principio, en nuestro ordenamiento jurídico, toda vez que en razón del principio 
de legalidad todo lo que no está prohibido está permitido [...] cabe adentrarse al análisis del caso concreto traído a resolver, a fin de evaluar si se encuentran reunidos en los presentes, los recaudos que hacen procedente la solicitada autorización judicial [...] en estos casos de TRHA, lo basal es la voluntad procreacional y no el dato genético. Lo que sucede es que al no regularse la gestación por sustitución, el código no se apartó de la regla que la madre sigue al vientre, pues no tuvo en miras la disociación entre gestante y maternidad socioafectiva. Lo que sí hubiese sucedido ciertamente, si la regulaba [...] resultaría contradictorio aplicar la regla del artículo 562 a los casos de gestación por sustitución, cuando el propio sistema jurídico [...], reconoce a la voluntad procreacional como determinante del vínculo filial, a más de implicar derechamente una grave vulneración al derecho a la filiación del niño o niña $[\ldots .$.$] y de su derecho a la identidad subjetiva [\ldots .$.

Por último, se acompaña la reseña de otro precedente que tiene puntos de contacto respecto de los hechos y argumentos fundantes de la decisión ${ }^{32}$. En particular, nos limitamos a un sumario de la estrategia seguida por el juez para integrar el sistema y un extracto del dictamen de la Subdirectora de Derechos Humanos y Acceso a la Justicia de la Suprema Corte de Justicia de Mendoza, cuyo texto se traslada a la sentencia judicial en la parte que contiene un encuadre de la voluntad procreacional.

Respecto de la integración del sistema, el juez interviniente dijo:

[...] la sanción de CCC no solo implica un significativo y moderno cambio normativo, sino que también concreta la adecuación del Derecho secundario civil y comercial al paradigma constitucional vigente [...] la aplicación directa de normas convencionales, en casos como el presente, máxime ante la falta de previsión legal específica, deviene necesaria e importa una especie de proceso de adición normativo por el que el juez, en su rol de integrador del Derecho y en cumplimiento del mandato legal, adiciona o añade algo al texto legal para que compatibilice con la Constitución Nacional. Desde esta perspectiva integradora del Derecho se impone el análisis de la técnica de la gestación por sustitución en el origen del derecho a la vida familiar y en particular a la conformación de la familia, puesto que el mismo, así como la protección de la familia constituyen uno de los derechos esenciales garantizados por la normativa y la jurisprudencia del Sistema Interamericano de Derechos Humanos [... En Esta línea de interpretación, merece destacarse las argumentaciones del caso 'Artavia Murillo y otros vs. Costa Rica', del 28/11/2012, en el que la Corte Interamericana de Derecho Humanos concreta y delinea el derecho a la vida familiar en términos claros cuyas conclusiones resultan aplicables a nuestro caso [...].

\footnotetext{
${ }^{32}$ Juzgado de Familia No 2 Mendoza, 6.9.2017.
} 
Respecto de la voluntad procreacional, la Subdirectora de Derechos Humanos y Acceso de Justicia expresó:

[...] se trata de hacer prevalecer la voluntad y el compromiso de emplazamiento familiar de los comitentes. Es que el principio mater semper certa est, según el cual la maternidad es siempre cierta y se determina por el parto, se ve destruido en la GS, ya que quien lleva adelante el embarazo no es la misma persona que posee la voluntad procreacional, y como en este caso, es distinta también a quien ha proporcionado el óvulo (...) Esta tercera persona carece de esa voluntad; por ende, aun cuando por aplicación de los principios legales (...) correspondería la atribución de la maternidad a la gestante, falta el elemento central que atribuye o determina la filiación en las Técnicas de Reproducción Humana Asistida: la voluntad procreacional [...] madre es querer ser madre y si ese deseo o querer no existe, resulta injusto imponer a la persona gestante la maternidad, la que en los hechos no se hará efectiva $[\ldots .$.$] .$

\section{CiERre}

Como expresamos, el CCC recepta en sus normas expresa e implícitamente la socioafectividad y con esta impronta extiende la protección a quienes formen parte de relaciones familiares que nacen del afecto, muchas de estas no se completan con lazos de parentesco.

La apertura que se observa encuentra respaldo en un sistema de principios y valores que reemplaza estructuras rígidas por flexibles, con el propósito de proteger a la persona en el contexto de su realidad familiar y social.

Desde esta perspectiva, pudimos observar cómo la socioafectividad penetra en las distintas formas de vivir en familia y explica por qué las familias deben ser estudiadas desde esta realidad vivencial.

En sintonía con esta visión plural respetuosa de la diversidad, se hizo un recorrido que buscó describir cómo la apertura que también se observa en filiación, permite ampliar los contornos de la socioafectividad.

Conforme lo expuesto, cuando el intérprete se encuentre frente al desafío de subsumir un caso en la norma, tendrá que desplegar una tarea que no se limite a lo que dice, sino que atienda a su finalidad. No debe realizar esta actividad aislando a la norma del todo, sino por el contrario, desde un lugar que facilite la vinculación con normas análogas y normas de fuente constitucional y convencional.

\section{BIBLIOGRAFÍA}

AzPIRI, Jorge, 2016: Derecho de familia (2 edición), Buenos Aires, Hammurabi.

BASSET, Úrsula, 2016: "Maternidad subrogada: determinar la filiación por el parto ¡es contrario a los derechos humanos?”, La Ley, 2016-C, 88. 
De la Torre, Natalia, 2016: "La triple filiación desde la perspectiva civil", Revista de Derecho Privado y Comunitario, 2016-I.

De la Torre, Natalia, 2015: "Pluriparentalidad: ¿por qué no más de dos vínculos filiales”, Derecho de Familia. Revista interdisciplinaria de doctrina y jurisprudencia, 2015-V-217.

Díaz De Gujjarro, Enrique, 1965: "La voluntad y la responsabilidad procreacionales como fundamento de la determinación de la filiación”, Jurisprudencia Argentina, 1965-III-21.

FAMÁ, María Victoria, 2017: Filiación por naturaleza y por técnicas de reproducción bumana asistida, Tomos I y II, Buenos Aires, La Ley.

FAMÁ, María Victoria, 2012: "Filiación”, en Julio Rivera (director) y Graciela Medina (coordinadores), Comentarios al Proyecto de Código Civil y Comercial de la Nación 2012, Abeledo Perrot, Ciudad Autónoma de Buenos Aires, 2012, pp. 419-440.

Gil Domínguez, Andrés, 2016a: "La triple filiación y el Código Civil y Comercial”, Derecho de Familia. Revista interdisciplinaria de doctrina y jurisprudencia, $\mathrm{N}^{\circ} 74$.

Gil Domínguez, Andrés, 2016b: "La filiación por poliamor (o múltiple filiación): una mirada constitucional y convencional”, Revista de Derecho Privado y Comunitario, 2016-I.

Gil Domínguez, Andrés, 2015a: El Estado constitucional y convencional de derecho en el Código Civil y Comercial, Buenos Aires, Ediar.

Gil Domínguez, Andrés, 2014: La voluntad procreacional como derecho y orden simbólico, Buenos Aires, Ediar.

Gil Domínguez, Andrés, FamÁ, María V. y Herrera, Marisa, 2006: Derecho constitucional de familia, Buenos Aires, Ediar.

Herrera, Marisa, 2015: “Sociafectividad e infancia: ¿de lo clásico a lo extravagante?”, en Silvia FERnÁndeZ (directora), Tratado de Derecho de niños, niñas y adolescentes, Tomo I, Buenos Aires, Abeledo Perrot, pp. 971-1012.

Herrera, Marisa, 2014a: "Comentario a los arts. 558 a 593", en A. Kemelmajer, M. Herrera y N. Lloveras (directoras), Tratado de Derecho de Familia, Tomo II, Santa Fe, Rubinzal Culzoni.

Herrera, Marisa, 2014a: "La noción de socioafectividad como elemento 'rupturista' del derecho de familia contemporáneo", Derecho de Familia. Revista interdisciplinaria de doctrina y jurisprudencia, $\mathrm{N}^{\circ} 66$.

Kemelmajer de Carlucci, A., Herrera, M. y Lloveras, N. (directoras), 2014: Tratado de Derecho de Familia, Tomos I y II, Santa Fe, Rubinzal Culzoni.

Krasnow, Adriana, 2018: "La adopción en función de cada realidad vital", Derecho de Familia. Revista interdisciplinaria de doctrina y jurisprudencia, No 83, AP/DOC/81/2018.

Krasnow, Adriana, 2017a: Tratado Derecho de las familias, Tomos I y III, Buenos Aires, La ley.

Krasnow, Adriana, 2017b: "El despliegue de la socioafectividad en el Derecho de las familias", Derecho de Familia. Revista interdisciplinaria de doctrina y jurisprudencia, No 81.

Krasnow, Adriana, 2017c: "La filiación por técnicas de reproducción humana asistida en el Código Civil y Comercial argentino. Un avance que permite armonizar la norma con la realidad", Revista de Derecho Privado, $\mathrm{N}^{\circ} 32$.

Krasnow, Adriana, 2016a: "Filiación por técnicas de reproducción humana asistida; gestación por sustitución y consentimiento informado en Argentina. Aportes y cambios introducidos por el Código Civil y Comercial”, Revista Bioética y Derecho, Vol. 37.

Krasnow, Adriana, 2016b: "El Título Preliminar del Código Civil y Comercial y su incidencia en la filiación por TRHA. Un abordaje posible desde la visión de sistema”, Derecho de Familia. Revista interdisciplinaria de doctrina y jurisprudencia, $\mathrm{N}^{\circ} 76$.

Krasnow, Adriana, 2014: "La filiación y sus fuentes en el Proyecto de Reforma de Código Civil y Comercial 2012 en Argentina”, InDret, 1/2014. 
KraSnOw, Adriana, 2003: "La verdad biológica y la voluntad procreacional”, La Ley 2003-F, 1150. Lamm, Eleonora, 2017: “Actualidad bioética en el mundo”, Abeledo Perrot AP/DOC/87/2017.

Lamm, Eleonora, 2015: "Una vez más sobre gestación por sustitución. Porque la realidad sigue exigiendo legalidad”, Derecho de Familia. Revista interdisciplinaria de doctrina y jurisprudencia, $2015-\mathrm{V}-137$.

LAMM, Eleonora, 2013: “Gestación por sustitución”, InDret, julio 2012.

LAMm, Eleonora, 2012: "La importancia de la voluntad procreacional en la nueva categoría de filiación derivada de las técnicas de reproducción humana asistida", Revista Bioética y Derecho, Vol. 24.

Lово, Paulo, 2010: "Socioafectividade no Direito de Familia: a persistente trajectoria de un conceito”, en M. B. Dias, E. Ferreira Bastos y N. Martins Moraes (coordinadores), Afecto y Estructuras familiares, Belo Horizonte, IBDFAM, p. 453.

LunA, Florencia, 1999: "Problemas en torno a las nuevas formas de procrear", en Decisiones de vida y muerte, Buenos Aires, Sudamericana.

Mizrahi, Mauricio, 2006: Familia, matrimonio y divorcio ( $2^{\circ}$ edición), Buenos Aires, Astrea.

Ravetllat Bellesté, Isaac y Pinochet Olave, Ruperto, 2015: “En interés superior del niño en el marco de la Convención Internacional sobre los Derechos del Niño y su configuración en el Derecho Civil chileno", Revista Chilena de Derecho, Vol. 42, No 3, p. 903 a 934.

Rosatti, Horacio, 2016: El Código Civil y Comercial desde el derecho constitucional, Santa Fe, Rubinzal Culzoni.

SAmbrizzi, Eduardo, 2016: "La maternidad subrogada y la declaración de inconstitucionalidad del art. 562 del Código Civil y Comercial", Revista Derecho de Familia y de las Personas, 2016 (mayo), p. 179.

Turner Saelzer, Susan-Molina Pezoa, Marcia y Momberg Uribe, Rodrigo, 2000: "Técnicas de reproducción humana asistida. Una perspectiva de los intereses del hijo”, Revista de Derecho (Valdivia), Vol. 11, p. 13.

Normas jurídicas citadas

LEY N 26.061 sobre Protección integral de los derechos de niñas, niños y adolescentes. Publicada el 26 de octubre de 2005.

Decreto 415, reglamentario de la ley 26.061. Publicado el 18 de abril de 2006.

LEy No 26.618 de Matrimonio Civil. Publicada el 22 de julio de 2010.

LEY No 26.657 sobre Salud Mental. Publicada el 3 de diciembre de 2010.

LEY N 26.862 sobre Acceso integral a los procedimientos y técnicas médico-asistenciales de reproducción médicamente asistida. Publicada el 26 de junio de 2013.

Decreto 953, reglamentario de la ley 26.862. Publicado el 19 de julio de 2013.

LEY No 26.994, aprueba el CCC argentino. Publicada el 8 de octubre de 2014.

Jurisprudencia citada

Juzgado Familia $4^{\circ}$ Nom. Córdoba, sentencia de fecha 28 de junio 2010. RDF 2011-I.

CORTE Interamericana de Derechos Humanos, sentencia de fecha 28 de noviembre de 2012. www.corteidh.or.cr

JuZGado Nacional $1^{\circ}$ inst. $\mathrm{N}^{\circ}$ 86, sentencia de fecha 18 de junio de 2013. La Ley 2013-D, 195.

Juzgado de $1^{\circ}$ inst. Civil, Comercial y Laboral Curuzú Cuatiá, sentencia de fecha 28 de junio de 2016. La Ley AR/JUR/47163/2016. 
Juzgado Familia No 7 Viedma, sentencia de fecha 6 de julio de 2017. www.saij.gov.ar.

Juzgado de Familia No 2 Mendoza, sentencia de fecha 6 de septiembre de 2017. La Ley AR/ JUR/60950/2017.

Tribunal Colegiado de Familia No 4 Rosario, sentencia de fecha 13 de octubre de 2017. www. saij.gov.ar

Tribunal Colegiado de Familia N ${ }^{\circ}$ 7, sentencia de fecha 5 de diciembre de 2017. www.saij.gov.ar 